\title{
BIOLOGICAL TREATMENT OF WATER CONTAMINATED BY HYDROCARBONS IN THREE-PHASE GAS-LIQUID-SOLID FLUIDIZED BED
}

K. ALLIA*
N. TAHAR
L. TOUMI
Z. SALEM

\author{
Faculty of Science Engineering \\ Department of Processes Engineering \\ Laboratory of Processes and Environment Engineering \\ University of Sciences and Technology «Houari \\ Boumediene » \\ U.ST.H.B - BP 32 El-Alia - Bâb - Ezzouar 16111 Alger
}

Selected from papers presented in $9^{\text {th }}$ International Conference on Environmental

Science and Technology (9CEST2005)

*to whom all correspondence should be addressed e-mail: khedidjaallia@yahoo.fr , kallia@usthb.dz

1-3 September 2005, Rhodes island, Greece

\begin{abstract}
Biological treatment has been carried out in two different systems: aerated closed and threephase fluidized bed reactors for hydrocarbons removal from refinery wastewaters. For the two systems, hydrodynamic study allowed the determination of operating conditions before treatment experiments. Then, in a second time, biological treatments have been conducted in the same operating conditions. The obtained results showed that in the three-phase fluidized bed we can degrade hydrocarbons more rapidly than in a closed aerated bioreactor.

Among the different appropriate techniques available to create efficient contacts between phases, the three-phase fluidization G/L/S where carrier particles are moving inside the reactor seems very interesting. It allows an intimate contact between phases and present many advantages concerning hydrodynamic and mass transfer phenomena. In fact, depending on operating conditions and the bubble flow behaviour, the three-phase fluidized bed could display different flow regimes

In these systems called bioreactors the solid particles covered with a biofilm are fluidized by two ascending flows of air and contaminated water. With favourable operating conditions, from a hydrodynamic and mass transfer point of view, the pollutant can be biologically degraded up to $90 \%$.

Until this date, the three-phase bioreactors modelling remains very complex because it required taking into account several factors: the pollutant biodegradation rate in the biofilm, the bioreactor hydrodynamic characteristics, and the reactant interfacial gas-liquid and liquidsolid mass transfer. Thus the essential purpose of modelling is to integrate the microbial kinetics with the reactor hydrodynamics. We can notice that a few models have incorporated both bioreactor hydrodynamics and microbial kinetics.

For the steady state bioreactor model, we generally assume that the particles are uniform in size, the biofilm is uniform in thickness, and the biofilm can be considered as homogeneous matrix through which oxygen and substrate diffuse and are consumed by the microbes. The liquid phase in the bioreactor substrate is considered to be axially dispersed while the gas phase is assumed to be in plug flow [2]. Rittmann (1997) proposed a model based on wake theory for predicting bed expansion and phase hold-ups for three-phase fluidized bed bioreactors. In this model he modified the correlation for the computation of the bioparticles drag coefficient $C_{D}[3]$. He also attempted to explain the biofilm detachment which can occur with three broad patterns: erosion, sloughing and scouring and assumed that the factors affecting detachment rates can be grouped into two categories (physical forces and microorganisms physiology in the biofilm).
\end{abstract}

KEYWORDS: Biological treatment, refinery wastewaters, three-phase fluidized bed G/L/S, closed aerated bioreactor. 


\section{INTRODUCTION}

The development of microbial biofilm has been the subject of many investigations; usually to elucidate a large number of undesirable effects concomitant with biofilm growth. Beside the medical fields, induction and acceleration of corrosion processes caused by biofilm. On the other hand, biofilm can be advantageously used for industrial purpose as in wastewater treatment, selective removal of targeted metals from mining and refining effluent, improvement of secondary oil recovery procedure in oil industry. In that purpose, many different biofilm reactors have been designed to answer the variety of research questions and industrial applications. These treatments based on the use of micro-organisms eliminate the principal pollutants (metals and organic substances) by decomposing the inorganic and organic pollutants in simple products.

The three-phase fluidization G/L/S where carrier particles are moving inside the reactor seems to be very interesting. It allows an intimate contact between phases and present many advantages concerning hydrodynamic and mass transfer phenomena. In these systems, called bioreactors the solid particles covered with a biofilm are fluidized by two ascending flows of air and contaminated water. With favourable operating conditions, from a hydrodynamic and mass transfer point of view, the pollutant can be biologically degraded up to $90 \%$.

Concerned by wastewater treatment in the petrochemical and refining industry, we focussed our study on the Algiers refinery, which treats $8532 \mathrm{~T} \mathrm{~d}^{-1}$ of crude oil and rejects $6144 \mathrm{~m}^{3} \mathrm{~d}^{-1}$ of used water in the various processes with concentrations reaching an average of $239 \mathrm{mg}$ $\mathrm{HC}^{-1}$. This concentration is too high compared to the admissible value given by the Algerian norm (20 $\mathrm{mg} \mathrm{l}^{-1}$ (1993)) and the actual international norm.

Before the experiments in the bioreactor, we initially analyzed the quality of the refinery wastewater by measuring various parameters of pollution such as temperature, $\mathrm{pH}, \mathrm{COD}$, $B O D, H C$, and the MES. We determined the nature of the flow and studied the operating stability of our bioreactor for different operating conditions. Then, operations of hydrocarbons biodegradation have been led for refinery wastewaters, in two different systems: an aerated closed agitated bioreactor and a three-phase fluidized bed (G/L/S) bioreactor. Finally, we compared and discussed the effectiveness of the two bioreactors.

Until this date, the three-phase bioreactors modelling remains very complex because it required taking into account several factors: the pollutant biodegradation rate in the biofilm, the bioreactor hydrodynamic characteristics, and the reactant interfacial gas-liquid and liquidsolid mass transfer. Thus, the essential purpose of modelling is to integrate the microbial kinetics with the reactor hydrodynamics. We can notice that, a few models have incorporated both bioreactor hydrodynamics and microbial kinetics (Wisecarver and Fan, 1989; Petersen and Davison, 1995) [1].

For the steady state bioreactor model, Fan assumed that the particles are uniform in size, the biofilm is uniform in thickness, and the biofilm can be considered as homogeneous matrix, through which, oxygen and substrate diffuse and are consumed by the microbes. The liquid phase in the bioreactor substrate is considered axially dispersed while the gas phase is assumed to be in plug flow [2]. Rittmann (1997) proposed a model based on wake theory for predicting bed expansion and phase hold-ups for three-phase fluidized bed bioreactors. In this model, he modified the correlation for the computation of the bioparticles drag coefficient $C_{D}[3]$. He also attempted to explain the biofilm detachment, which can occur with three broad patterns: erosion, sloughing and scouring and assumed that the factors affecting detachment rates can be grouped into two categories (physical forces and micro organisms physiology in the biofilm).

\section{EXPERIMENTAL UNIT AND PROCEDURE}

Two sets of experiments were carried out: three-phase fluidized bed bioreactor, and aerated closed agitated bioreactor.

\subsection{The three-phase fluidized bed}

The equipment used was laboratory scale and a schematic diagram is shown in Figure 1, it is essentially composed by the following elements: the three-phase fluidized bed column (1) (ID $=9,4 \mathrm{~cm}$ and height equal $100 \mathrm{~cm}$ ), the disengagement zone (2), the distributors, the calming 
zone (3), the feeding zone of water and gas (4), and the zone of liquid phase recirculation (12).

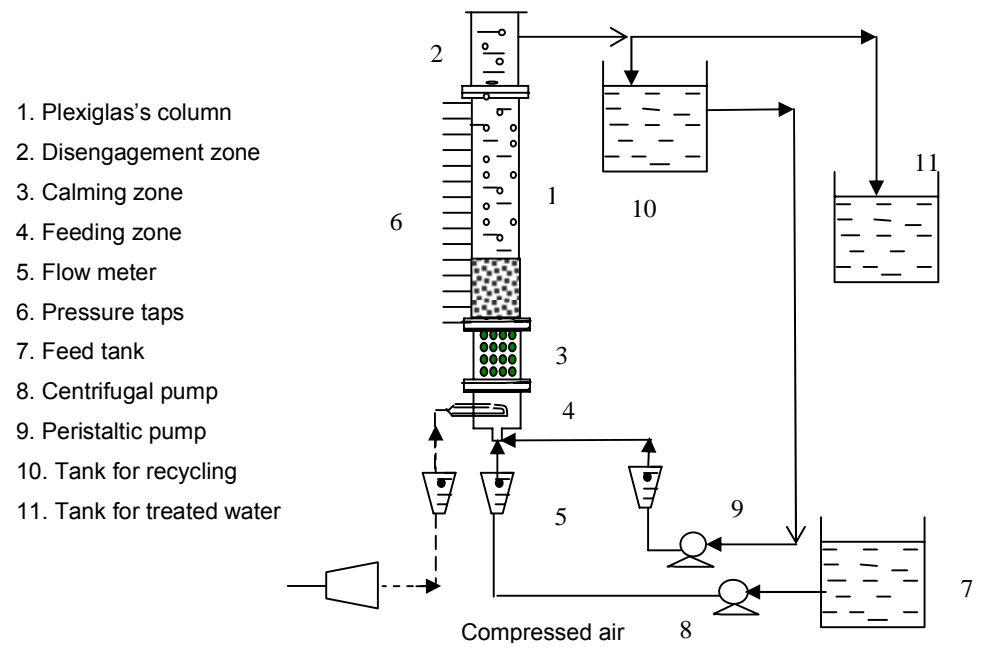

Figure 1. experimental flow sheet of three-phase fluidized bed

Along the column, fourteen pressure taps are located at $3 \mathrm{~cm}$ intervals for the determination of pressure profile. The feeding zone is a cylindrical part of Plexiglass equipped with two entries located at the bottom and side of the column for the water and gas supply.

Compressed air was used for aeration $\left(0-90 \mathrm{I} \mathrm{h}^{-1}\right)$. The air flow was selected in order to ensure a sufficient dissolved oxygen concentration for the micro-organisms breathing and to have at the same time a dispersed bubbles mode flow.

The circulation of the liquid phase can be carried out in two manners: In closed or open loop. In the first part of the study relating to the hydrodynamics, the liquid phase used is the tap water. In the second part refinery wastewaters were used (Table 1).

Table 1. Parameters of the refinery wastewaters

\begin{tabular}{cccccccc}
\hline Parameter & $\mathrm{pH}$ & $\mathrm{T}\left({ }^{\circ} \mathrm{C}\right)$ & $\begin{array}{c}\mathrm{COD} \\
\left(\mathrm{mg} \mathrm{l}^{-1}\right)\end{array}$ & $\begin{array}{c}\mathrm{BOD} \\
\left(\mathrm{mg} \mathrm{l}^{-1}\right)\end{array}$ & $\begin{array}{l}\mathrm{O}_{2} \\
\left(\mathrm{mg} \mathrm{l}^{-1}\right)\end{array}$ & $\begin{array}{c}\mathrm{NO}_{3}^{-} \\
\left(\mathrm{mg} \mathrm{l}^{-1}\right)\end{array}$ & $\begin{array}{l}\mathrm{PO}_{4}{ }^{2-} \\
\left(\mathrm{mg} \mathrm{l}^{-1}\right)\end{array}$ \\
\hline Refinery wastewaters & 7.36 & 23 & 211.2 & 175 & 2.85 & 0.197 & 0.0015 \\
\hline
\end{tabular}

Different biofilms carriers can be used as sand, volcanic rock, expanded clay, plastic pieces, tubing or corrugated plastic plates. The sand has been chosen for its availability and its fine granulometry in order to have an important specific surface and $10 \%$ of the column volume was filled with solid particles.

The experimental conditions used are listed in Table 2.

Table 2. Operating conditions

\begin{tabular}{lccccccc}
\hline Parameter & $\begin{array}{c}\mathrm{Ul} \\
\left(\mathrm{cm} \mathrm{s}^{-1}\right)\end{array}$ & $\begin{array}{c}\mathrm{Ug} \\
\left(\mathrm{cm} \mathrm{s}^{-1}\right)\end{array}$ & $\begin{array}{c}\rho_{\mathrm{s}} \\
\left(\mathrm{kg} \mathrm{m}^{-3}\right)\end{array}$ & $\begin{array}{c}\rho_{\mathrm{l}} \\
\left(\mathrm{kg} \mathrm{m}^{-3}\right)\end{array}$ & $\begin{array}{c}\mathrm{dp} \\
(\mu \mathrm{m})\end{array}$ & $\begin{array}{c}\mathrm{W} \\
(\mathrm{kg})\end{array}$ & $\mathrm{H}_{0} / \mathrm{D}_{\mathrm{c}}$ \\
\hline value & $0,03-0,6$ & $0,06-0,14$ & 2560 & 1000 & 283 & 1 & 1,06 \\
\hline
\end{tabular}

\subsection{Aerated closed agitated bioreactor}

The experimental unit is composed of two identical glass reactors with $18 \mathrm{~cm}$ inner diameter and $24 \mathrm{~cm}$ height. The agitation mechanical system (50 and $2500 \mathrm{rpm}$ ) and aeration system ensured the propagation of the compressed air. The stirring velocity and the air flow rate allowing a good circulation and aeration inside the reactor were determined experimentally by hydrodynamic study.

The different analysis and methods of measure are shown in Table 3. 
Table 3. Methods of measure and analysis of parameters

\begin{tabular}{lllllll}
\hline Parameter & $\mathrm{pH}$ & COD & BOD & MES & $\begin{array}{c}\text { Dissolved } \\
\mathrm{O}_{2}\end{array}$ & Hydrocarbons \\
\hline Method & $\begin{array}{l}\text { electrode } \\
\text { method }\end{array}$ & $\begin{array}{l}\text { Potassium } \\
\text { dichromate } \\
\text { method }\end{array}$ & $\begin{array}{l}\text { manometric } \\
\text { method }\end{array}$ & $\begin{array}{l}\text { filtration } \\
\text { on } \\
\text { paper } \\
\text { filters }\end{array}$ & $\begin{array}{l}\text { electrode } \\
\text { method }\end{array}$ & $\begin{array}{l}\text { infra-red } \\
\text { spectrophotometer }\end{array}$ \\
& & & & \\
\hline
\end{tabular}

\section{EXPERIMENTAL RESULTS AND DISCUSSION}

\subsection{Hydrodynamic study}

Prior to treatment experiments, preliminary hydrodynamic experiments were carried out with the two systems to confirm the operating stability, to identify the nature of mode flow and to determine some hydrodynamic parameters such as the minimum fluidization velocity, the pressure drop, the expansion, the bed porosity, the gas retention and the stirring velocity.

For the fluidized bed, the experimental values of the minimum fluidization velocity were compared with those of the literature and the average deviation was $9 \%$. Concerning the bed expansion, with small liquid velocities, we observed a bed contraction when we injected the gas, and at higher liquid velocities, we noted a bed expansion (figure 2). These behaviours are usually described in the literature [2].

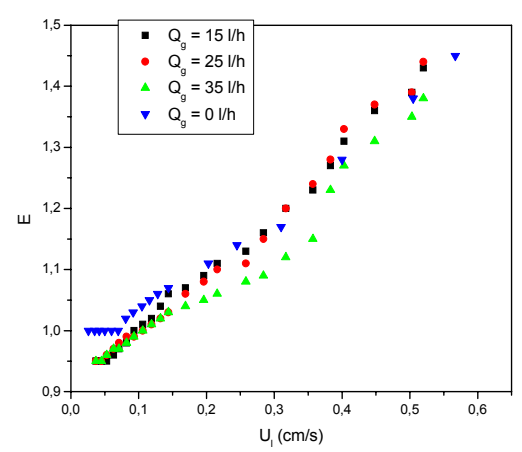

Figure 2. Bed expansion evolution in FBB

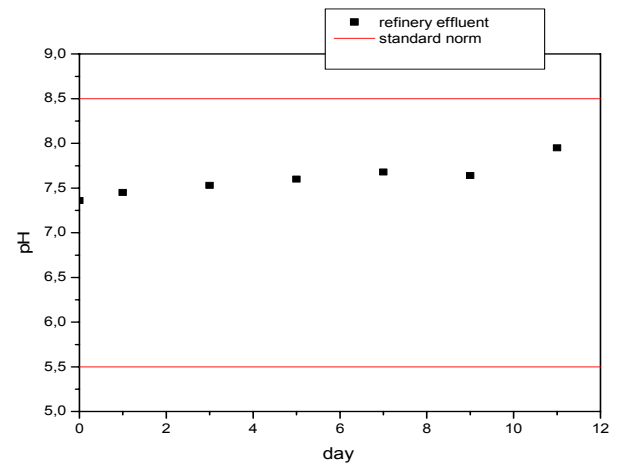

Figure 3. $\mathrm{pH}$ evolution in FBB

The set of results obtained in hydrodynamic study confirm the three phase fluidized bed operating stability, at dispersed bubbles mode flow, and are in good agreement with certain previous works (Ostergaard, Stewart, Kim) [ 4 ].

For the aerated closed reactor, we have studied the influence of the air flow rate and the stirring velocity on the gas retention $\alpha$.

$\alpha=\frac{H\left\llcorner-H_{0}\right.}{H L}$, where $H_{L}$ and $H_{0}$ are the aerated liquid height and initial liquid height.

We noticed that for a low gas flow rate and low stirring velocities the homogenisation is not carried out, indeed sand settled at the bottom of the reactor and we had a bad dispersion of gas in the suspension. From the stirring velocity of $300 \mathrm{rpm}$ and for an air flow rate of $2835 \mathrm{ml}$ $\mathrm{min}^{-1}$, we obtained maximum gas retention without vortex phenomenon and the maintenance in suspension of sand particles (see Figures 8 and 9 ). These parameters were selected for the biological treatment reactor.

\subsection{Hydrocarbons biodegradation in the three-phase fluidized bed}

The biodegradation of the hydrocarbons in the three phase fluidized bed bioreactor requires the presence of specific bacteria immobilized on particles. In order to create this medium, sand particles were seeded by the refinery wastewater during 7 days. The identification tests confirmed the presence of bacteria type pseudomonas aeroginosa specific to the mediums contaminated by hydrocarbons. Before beginning the treatment, we have verified the ratios: $\mathrm{COD} / \mathrm{BOD}$, and $\mathrm{BOD} / \mathrm{N} / \mathrm{P}$. We obtained $\mathrm{COD} / \mathrm{BOD}=1,2(<2,5)$. 
The wastewater circulation was carried out through the bed of bioparticules in closed loop using a peristaltic pump. The Liquid flow recirculation and the gas flow rate were respectively $1,5 \mathrm{Q}_{\mathrm{Imf}}$ and $50 \mathrm{I} \mathrm{h}^{-1}\left(\mathrm{U}_{\mathrm{l}}=0,133 \mathrm{~cm} \mathrm{~s}^{-1}\right.$ and $\left.\mathrm{U}_{\mathrm{g}}=0,20 \mathrm{~cm} \mathrm{~s}^{-1}\right)$.

With these operating conditions, we noted the evolution of $\mathrm{pH}, \mathrm{T}, \mathrm{DO}, \mathrm{COD}, \mathrm{BOD}$ and \% $\mathrm{HC}$ removal.

The effluent $\mathrm{pH}$ is a determining factor for the activity of micro-organisms and for their selection. The values obtained of $\mathrm{pH}$ are in the norms and remain in the fixed limits for a good hydrocarbons biodegradation of $5.5<\mathrm{pH}<8.5$ (see Fig. 3).

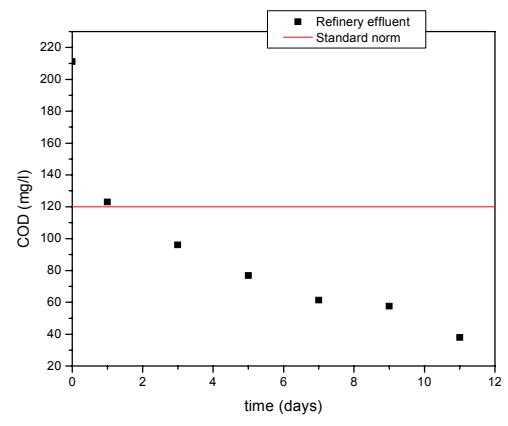

Figure 4. COD evolution in FBB

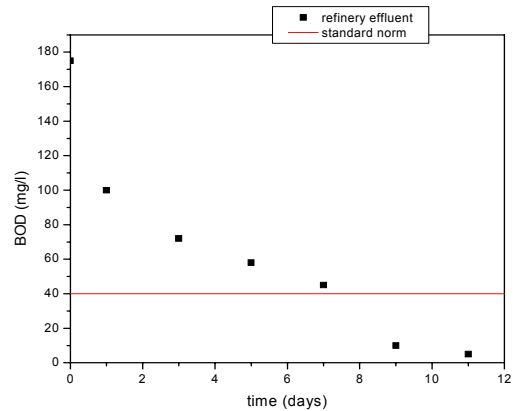

Figure 5. BOD evolution in FBB

We noticed a weak variation of temperature during the treatment but it remains below the norm and in fixed limits to have a good bacterial activity $\mathrm{T}_{\text {average }}=23$ and $26^{\circ} \mathrm{C}$.

Dissolved oxygen is an important parameter needed for micro-organisms respiration.

Its evolution is illustrated in figure 6 where we observe the increasing of dissolved oxygen from $2.85 \mathrm{mg} \mathrm{l}^{-1}$ at average values of $10-11 \mathrm{mg} \mathrm{I}^{-1}$.

We observed that the COD parameter decreases to reach the norm $\left(120 \mathrm{mg} \mathrm{I}^{-1}\right)$ during the first day (Figure 4). This reduction results from the mineralization of organic matter thus hydrocarbons biodegradation.

The evolution of BOD, is similar to that COD. Indeed, the BOD decreases during the treatment, to reach the fixed norm $40 \mathrm{mg} \mathrm{I}^{-1}$ after 7 days (Figure 5).

Rate hydrocarbons evolution was established by analysing the wastewater by IR. The IR spectre gives the density $D$ and indicates a pick at wavelength of $3000 \mathrm{~cm}^{-1}$. We have calculated the percent of hydrocarbons eliminated, and the results are presented in the figure 7. We notice a good hydrocarbons biodegradation during the treatment.

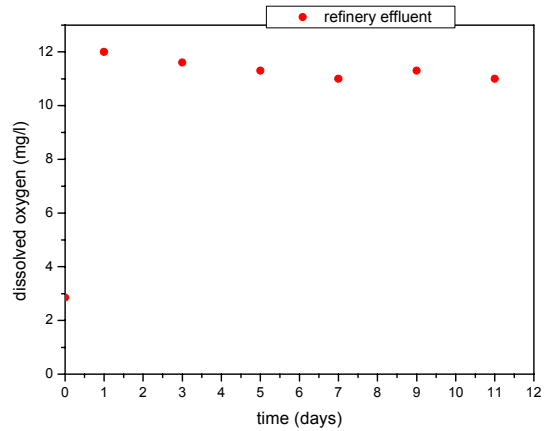

Figure 6. Dissolved oxygen concentration evolution in FBB

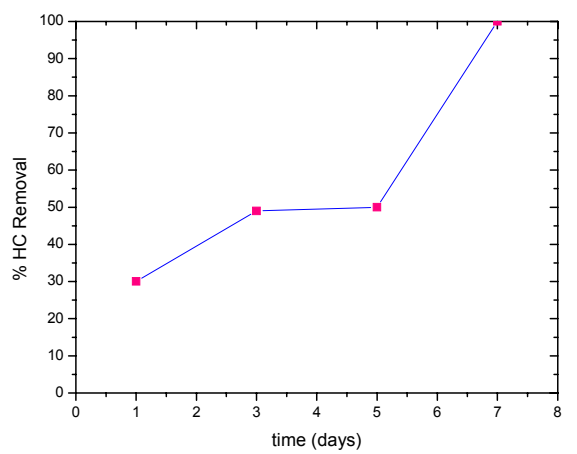

Figure 7. percentage $\mathrm{HC}$ removal evolution in FBB

\subsection{Hydrocarbons biodegradation in aerated closed agitated bioreactor}

To observe the influence of seeding on the biodegradation, we worked on two similar reactors, under the same operating conditions. Soluble COD and Hydrocarbons elimination are given to show the biodegradation evolution. We consider 
S.S: the first reactor containing sterile sand.

S.E: the second reactor containing seeded sand.

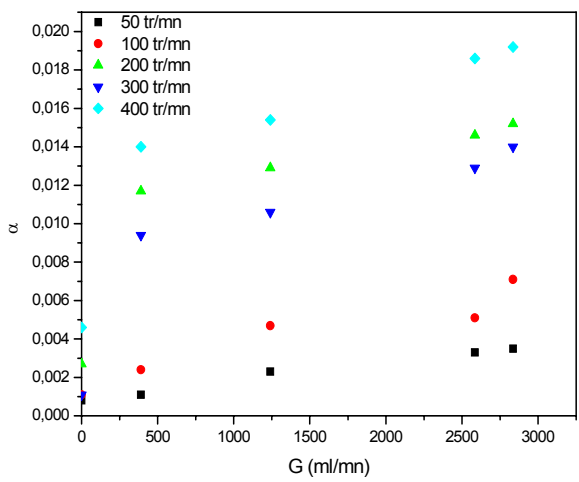

Figure 8. Gas retention evolution with airflow rate for different stirring velocities in a $\mathrm{CAB}$

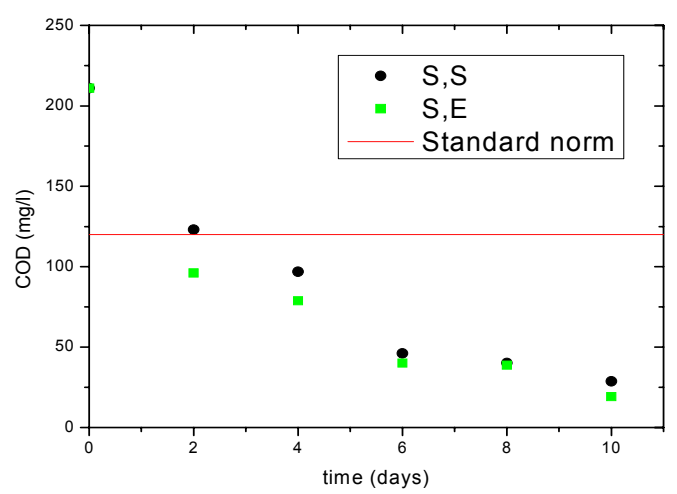

Figure 10. $\mathrm{COD}$ evolution in a $\mathrm{CAB}$

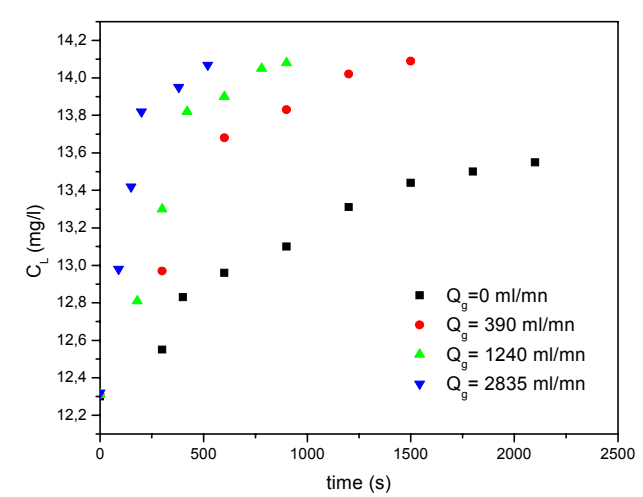

Figure 9. Dissolved oxygen concentration evolution for different airflow rates in a $C A B$

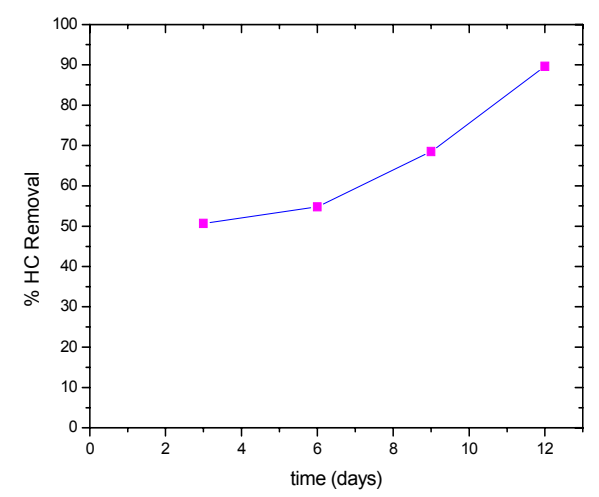

Figure 11. Hydrocarbons elimination in a $\mathrm{CAB}$

Soluble COD evolution (Figure 10) is in regression related on the mineralization of the organic matter and thus to hydrocarbons biodegradation. This reduction is a little more important in seeded reactor (S.E); this more intense activity is explained by the fact of the bacteria adaptation to the effluent. But starting from the 6th day the performances become almost similar what would be due to the deficit of the substrate. The final COD are very below to the standard norms of $120 \mathrm{mg} \mathrm{O}_{2} \mathrm{I}^{-1}$.

The comparison of hydrocarbons elimination between the seeded sand and the sterile sand showed a better effectiveness for the first, explained by the presence of the specific bacteria on the biofilm. The hydrocarbons elimination in the seeded bioreactor reaches $89.58 \%$ (figure 11).

In conclusion, after this treatment of refinery's wastewaters, in an aerated and closed bioreactor, we observed that all the parameters COD, $\mathrm{pH}$, orthophosphates and hydrocarbons decreased and are lower than the standards norms and in the seeded sand bioreactor the effectiveness is more important.

\section{CONCLUSION}

The results obtained show the efficiency of hydrocarbons contaminated wastewaters treatment in three-phase fluidized bed bioreactor. This typical bioreactor allows a good pollution removal rate. We note according to these results that the elimination of hydrocarbons in the three-phase fluidized bed bioreactor is better than that of the aerated 
agitated closed bioreactor. In the first, they are eliminated at $100 \%$, while in the second; they are eliminated between $87.77-95 \%$.

\section{REFERENCES}

1. Reese J., Silva E.M., Yang S.T. and Fan L. S. (1999) Fluidization Solids Handling and Processing, in Chap. 9: Industrial Applications of Three-Phase fluidization Systems, Noyes publications.

2. Fan L.S. (1989), Gas-Liquid-Solid Fluidization Eng., Butterworth, Boston.

3. Yu H. and Rittmann B.E. (1997), Predicting bed expansion and phase hold-ups for three-phase fluidized-bed reactors with and without biofilm, Wat. Res., 31(10), 2064-2616.

4. Muroyama K. and Fan L.S. (1985), Fundamentals of Gas-Liquid-Solid Fluidization, AIChE J., 113(1), 1-32. 